\title{
VERACIDAD, AFABILIDAD Y LIBERALIDAD
}

Jaime Ruiz de Santiago*

RESUMEN: En el trabajo se profundiza la doctrina de Santo Tomás de Aquino relativa al hombre y a la sociedad, destacando la importancia de la justicia en la estructura social. La justicia, empero, implica no tan solo el cumplir con aquello que es estrictamente exigible, sino que también se requieren otras perfecciones para crear una sociedad auténticamente humana: tales son las virtudes que aquí se estudian.

\section{yose \\ TRUTH, AFFABILTY, AND LIBERALISM: \\ FORGOTTEN VIRTUES OF THE SOCIAL ORDER}

ABSTRACT: In this article, we will focus in-depth on Saint Thomas Aquinas' doctrine regarding man and society, highlighting the significance of justice in a social structure. Justice, however, implies not only fulfilling such things that are strictly demanding, but it also requires other perfections in order to create an authentic human society: those virtues will be studied in this article.

PALABRAS ClAVE: Suma Teológica, virtudes morales, justicia, partes potenciales, veracidad y mentira, afabilidad y adulación, liberalidad, avaricia y prodigalidad.

KEY WORDS: Suma Teológica, moral virtues, justice, potential parts, truth and lie, affability and adulation, liberalism, greed and extravagance.

RECEPCIÓN: 7 de mayo de 2016.

APROBACIÓN: 13 de septiembre de 2016.

* Departamento Académico de Estudios Generales, ITAM. 
CITAM Derechos Reservados.

La reproducción total o parcial de este artículo se podrá hacer si el ITAM otorga la autorización previamente por escrito. 


\section{VERACIDAD, AFABILIDAD Y LIBERALIDAD}

$\mathrm{E}_{\text {s de gran interés actual estudiar la doc- }}$ trina de Santo Tomás de Aquino relativa a la conducta humana y la vida moral, tanto en la que se refiere a la perfección de la persona individual como en la relativa a su situación como ser social.

En la presente reflexión procuraré exponer la íntima vinculación que en el pensamiento de Santo Tomás tienen el ser y el actuar en el hombre (parte I), para precisar el sentido que poseen las virtudes morales como perfecciones propias del actuar humano (parte II). Será necesario recordar algunas cuestiones relativas a las "partes" o "divisiones" de las virtudes en general y de aquellas morales en particular (parte III), a fin de comprender la importancia que poseen virtudes tales como la veracidad, la afabilidad y la liberalidad en la vida social (parte IV), en cuanto "partes" de la otra perfección social fundamental que es la justicia. Al ser estas una exigencia para una vida social plena o perfecta, se percibe que se trata de "detalles" espléndidos de una obra arquitectónica monumental cuyas proporciones y armonía permiten percibir la hondura y genialidad de su autor.

\section{Ser y actuar humanos}

No es fácil comprender el sentido e importancia que tiene para Santo Tomás que el ser humano actúe con verdad. Es, en el fondo, el medio 
a través del cual "se hace" la verdad, se perfecciona el propio ser y se acrecienta la bondad de las propias relaciones sociales.

Una de las características que presenta el hombre contemporáneo, sobre todo en las nuevas generaciones, es precisamente esa delicada sensibilidad frente a la verdad que se debe realizar en toda la conducta de los hombres concretos y singulares. Se desconfía, no sin razón, de los discursos que no van apoyados y encarnados en la existencia. Tras periodos de la historia, muchas veces presentes, en que una filosofía idealista - en verdad ideosofía - ha intentado hacer creer que "lo real es lo ideal" y que ha querido hacer pasar como realidades subsistentes y consistentes lo que es tan solo un conjunto de ideas, que ha pretendido dar satisfacción al ser humano únicamente a través del engarzamiento lógico y ordenado de puros conceptos, el hombre de nuestros días se ha vuelto desconfiado y por ello, naturalmente, se inclina a ver en la propia conducta una manifestación de credibilidad y confiabilidad.

En la medida en que se superan los falaces atractivos del pensamiento idealista, la reacción del hombre de nuestros días manifiesta un claro síntoma de salud mental. En esta inquietud puede, en estos momentos, recibir de Santo Tomás ayudas enormemente liberadoras. Esto, porque para el Aquinate la perfección humana no es obra únicamente del pensar bien, sino fundamentalmente del actuar bien, de hacer la verdad en la delicada trama de nuestra existencia.

Por estos motivos es saludable prestar oídos a la enseñanza del santo y hacer el esfuerzo por comprender una doctrina que hace referencia constante a la acción. ${ }^{1}$

El "hacer la verdad" en la existencia es, para Santo Tomás, todo el problema de la vida moral, cuya realidad más profunda exige la presencia de la virtud moral. Mas entiéndase que esta, la virtud moral, no forma parte del "tener" humano, sino de su "ser" fundamental.

${ }^{1}$ En la concepción de Santo Tomás, las consideraciones relativas a la acción siguen a las concernientes al ser. No debe olvidarse nunca la primacía del nivel metafísico. 
Cuando en la Antigüedad Aristóteles sostenía que la virtud pertenece a la categoría de cualidad, quería significar que implica una modificación profunda del ser humano. Del ser, no del tener. La virtud moral representa esa transformación que el hombre logra realizar en su mismo ser para hacer posible el logro de su perfección como ser humano. Es así como se puede hablar, en el punto de arranque de toda vida humana, de una estructura ontológica o metafísica gracias a la cual somos precisamente seres humanos - estructura que, por naturaleza, requiere un similar análisis metafísico para ser descubierta-y la modificación que, a través de sus acciones, el hombre va realizando de tal estructura, en la medida en que, a través de sus actos libres, consigue conducir su propio ser personal a niveles de alta perfección o hundirlo en regiones de corrupción y degradación. Así, hay un punto de partida — en el cual existe estricta igualdad en todos los seres humanos - y un punto de llegada - en el que existe marcada diferenciación-: ambos se localizan en el nivel de la propia estructura humana.

Ninguno de tales puntos es despreciable: no lo es el de partida, por ser el centro de sustentación de una dignidad absoluta y de derechos inalienables que permanecen incluso a través de todos los errores y de todas las malformaciones que se puedan realizar; no lo es tampoco el punto de llegada, porque tal es el resultado de la aventura existencial y personal que cada hombre realiza.

Por el punto de partida nos reconocemos como seres humanos y como participaciones inigualables del ser absoluto; por el punto de llegada nos contemplamos como el resultado de nuestros propios proyectos y acciones. Pues bien, hacer la verdad del propio ser es precisamente el sentido de la virtud moral, así como sumir al propio ser en el error y la corrupción es resultado de su contrario, el vicio moral. La virtud moral perfecciona al ser humano en la línea más profunda de su humanidad y es, en consecuencia, condición indispensable para hacer la verdad. Tan importante es el tema para el Aquinate que a él dedica toda la segunda sección de la segunda parte (II-II) de la Suma Teológica que es, vale la pena notarlo, la parte más amplia de su genial obra: a ella le ha dedicado un total de 189 cuestiones. 
"Hacer la verdad" no es otra cosa que realizar el bien, pues este último, el bien, representa la verdad propia del ser humano. Por ello, el bien del cual se trata no es el ontológico o metafísico, que se da en el ser humano en su estructura primera y original, sino el bien moral, que implica necesariamente la intervención de actos humanos o libres puestos por el ser humano de manera inteligente y voluntaria y como realización de la perfección humana que se presenta siempre como posible. En consecuencia, el "hacer la verdad" posee también un significado moral: tarea del ser humano es "hacer la verdad moral", que es la que le corresponde como propia y específica.

Pero para "hacer la verdad" (moral) es necesario, tal como lo muestra Santo Tomás al tratar el problema de la conciencia y especialmente de la conciencia errónea, ${ }^{2}$ "estar en la verdad”. Si no se está en la verdad no se puede hacer la verdad. Con esto, como hemos dicho, es toda la temática de la conciencia moral la que se plantea, pues es gracias a ella que el hombre puede estar en la verdad en sus circunstancias concretas y singulares. Para hacer la verdad el ser humano requiere estar en la verdad en su conciencia, y si esta se encuentra en el error, será imposible hacer la verdad en la acción y, en consecuencia, en la existencia. Quizá si la conciencia llega a encontrarse en el caso de un error invencible no se llegue a obrar un error, una falta imputable, mas será imposible hacer la verdad. Lo que aquí acontece es que no hacer la verdad no implica necesariamente hacer el error. De cualquier modo, lo que al presente nos interesa es que estar en la verdad es condición indispensable para hacer la verdad y por ello puede entenderse por qué la indiferencia hacia la verdad representa una posibilidad de graves

${ }^{2}$ Esta temática es analizada en "Conciencia y verdad", del entonces cardenal Joseph Ratzinger, en Ser cristiano en la era pagana, 1995, Madrid, Encuentro. A esta traducción le faltan las notas de pie de página que aparecen en Valeurs pour un temps de crise, 2005, París, Parole et Silence, pp. 51-84, que son muy esclarecedoras y remiten a una buena bibliografía. Entre los artículos citados en la nota 19 (p. 80) debe destacarse el de J. B. Belmans, Le paradoxe de la consciente erronée d'Abelard à Karl Rahner. Es también muy importante la obra de J. M. Aubert La conciencia moral del cristiano, 1980, Barcelona, Herder. También me permito remitir a mi estudio "Naturaleza e implicaciones del juicio de conciencia erróneo en las perspectivas de la reflexión moral", Revista de Filosofía UIA, México, 1974, pp. 187-213. 
consecuencias. Es interesante señalar que los síntomas de esta situación son numerosos:

La indiferencia hacia la verdad se manifiesta, por ejemplo, en el hecho de estimar que la verdad y la falsedad, en ética, son solamente cuestión de gustos, de decisiones personales; o que sea suficiente con hacer lo que pensamos, sin preocuparnos de saber si lo que pensamos es verdadero o falso; o también, que el ser agradable a Dios no depende de la verdad de lo que pensemos de él, sino solamente de la sinceridad de nuestra creencia en lo que sostenemos. Es también ser indiferente a la verdad el creer que lo más importante para el hombre es buscar la verdad más que alcanzarla, puesto que en definitiva ella se nos escapa irremediablemente; y confundir, en consecuencia, el respeto debido a toda persona, cualesquiera que sean las ideas que profesa, con la negación de la existencia de una verdad objetiva. ${ }^{3}$

A esta situación hace referencia igualmente el texto de Norbert Wiener, quien estableció las bases de la cibernética, cuando dice: "Creamos o no en Dios y su mayor gloria, no todas las cosas nos resultan igualmente permitidas. Aunque Adolf Hitler pensara de otro modo, no hemos llegado aún al pináculo de la indiferencia moral que nos coloque más allá del Bien y del Mal. Y precisamente mientras retengamos una huella de discriminación ética, el uso de grandes poderes para propósitos bajos constituirá un equivalente moral total de la brujería y la simonía". ${ }^{4}$

En el origen último de esta actitud, que lanza de manera necesaria en el precipicio de la propia destrucción, está la negación de la verdad más profunda de nuestro ser, la negación de nuestro ser creatural y

${ }^{3}$ Juan Pablo II, Vivir según la verdad en la caridad, audiencia general del 24 de agosto de 1983, Documentation Catholique, núm. 1860, 1983, p. 983.

${ }^{4}$ Dios y Golem S A, 1967, México, Siglo XXI, p. 61, citado en El Hombre como creador y portador de cultura, vol. I, ITAM, México, 2000, pág. 113. Esta situación es el peligro que presenta la eugenesia liberal perfeccionadora, cuyas trágicas consecuencias son señaladas por Jürgen Habermas en El futuro de la naturaleza humana. ¿Hacia una eugenesia liberal?, 2002, Barcelona, Paidós, pp. 64-75, citado en El hombre como creador y portador de cultura, pp. 90-115. 
dependiente, la ambición de tornarnos en seres absolutos y totalmente autosuficientes. Con ello la dimensión metafísica y la moral vuelven nuevamente a tocarse: para hacer la verdad es necesario previamente estar en la verdad.

Como se ve, el punto central de la moral de Santo Tomás se encuentra en el bien moral, verdad de la acción humana. Esto es de interés porque permite comprender, con tan solo analizar la estructura de las cuestiones que integran la II-II de la Suma Teológica, los pilares de apoyo de la moral tomista.

Al analizar el verdadero sentido e importancia de la ley en el pensamiento de Santo Tomás de Aquino ${ }^{5}$ es fácil percibir, por ejemplo, que el tratamiento general que hace este autor de las materias morales descansa finalmente en los conceptos de bondad, de fin, de perfección humana, y que el tema de la ley ocupa un lugar secundario y subordinado. Por ello, al contrario de lo que se advierte en la moral kantiana $\mathrm{y}$ en todas aquellas doctrinas que se apoyan en la misma, la moral tomista es radicalmente una moral del bien y no de la obligación, de la conciencia y no del deber ser, del amor y no de la sanción.

Al estudiar el modo concreto como el ser humano hace la verdad, es decir, a través de las virtudes, se constata que de igual modo la II-II de la Suma Teológica está construida fundamentalmente sobre el estudio de estas últimas, de su naturaleza y de sus diferentes partes, para continuar con el estudio de sus opuestos - los vicios_-, y pasar de este modo a la exposición del don sobrenatural correspondiente (estamos en una obra de naturaleza teológica) y terminar, por último, con la exposición de los preceptos que se relacionan con la virtud. Como señala Teófilo Urdanoz, estos últimos son "elementos extrínsecos del orden moral, o del bien de la virtud [...]: los positivos, sobre actos virtuosos necesarios al fin, y los negativos o prohibitivos, sobre los vicios que destruyen ese obrar virtuoso necesario". ${ }^{6}$

${ }^{5}$ Se encuentra una muy buena presentación de este tema en J. M. Aubert, Ley de Dios, leyes de los hombres, 1979, Barcelona, Herder. Cfr. Jaime Ruiz de Santiago "Sentido e importancia de la ley en Santo Tomás de Aquino", en Revista de Filosofía UIA, 1969, pp. 217-240.

"Introducción" a Suma Teológica, 1959, Madrid, BAC, vol. VII, p. 18. Este volumen contiene las qq. 1-46. 
La conclusión que se obtiene es semejante a la anterior: a diferencia de lo que acontece en muchos autores y contemporáneos e incluso en muchos manuales que se dicen o se consideran "tomistas", la doctrina moral de Santo Tomás se centra en las nociones de bien, de amor y de virtud y considera como elementos periféricos y extrínsecos los tratados referentes a preceptos morales positivos y negativos.

En relación con autores anteriores, la postura de Santo Tomás posee gran originalidad y frescura y se puede decir lo mismo de muchos de los autores posteriores.

\section{Las "partes" o "divisiones" de las virtudes}

Hemos visto que las virtudes morales son perfecciones principales que abren la puerta y ejercen su influjo sobre todo un mundo de perfecciones derivadas. Esto nos lleva a aclarar el sentido que tiene hablar de las "partes" de las virtudes.

De manera breve y esquemática, es necesario recordar que hay tres clases de "totalidades" o de "todos" (II-II, q. 48): ${ }^{7}$ la totalidad esencial o universal, que se presenta entre el género con relación a sus especies (así, por ejemplo, el animal constituye un todo esencial); la totalidad cuantitativa o integral, que se presenta entre un compuesto con relación a sus componentes (así, por ejemplo, el árbol respecto a las hojas, el tronco a las raíces) y la totalidad virtual o potencial, que se da entre un poder completo y principal con relación a los poderes parciales y secundarios (así, por ejemplo, el poder del jefe con relación a sus secretarios y ayudantes).

A estas especies de "totalidades" corresponden diferentes clases de "partes": las partes esenciales o subjetivas, que se encuentran contenidas debajo de un género (hombre y bestia respecto de animal), las partes integrales que implican siempre una totalidad física (raíz, tronco, hojas respecto de árbol) y las parte potenciales que son de naturaleza cualitativa y dicen referencia a un poder total (ayudantes respecto del poder del jefe).

${ }^{7}$ Suma Teológica, 1956, Madrid, BAC, vol. VIII. El volumen contiene las qq. 47-79. 
Todo ello para entender que las virtudes morales o principales se integran o permiten la aparición de otras virtudes morales que desempeñan el papel de partes. En sentido estricto, las únicas partes que pueden aparecer con las virtudes morales son las esenciales o subjetivas y las potenciales: las virtudes morales son especies (totalidades esenciales) y totalidades potenciales (de naturaleza cualitativa). Como las partes integrales suponen un todo corporal, no son posibles en el universo de las virtudes morales, y cuando se habla de ellas se hace tan solo en sentido metafórico: estas partes (cuasi integrales) no corresponden a tales virtudes en cuanto a su ser sino tan solo en cuanto a su tarea o función, en la medida en que ayudan a realizar el acto perfecto de la virtud, al modo como las partes integrales (físicas) colaboran en la constitución del todo.

En la presente reflexión interesa centrarnos en algunas de las partes de la justicia. Ya en otra ocasión ${ }^{8}$ nos referimos a las distintas especies de justicia. Esta aparece como la perfección propia del apetito racional (voluntad), gracias a la cual se da de manera constante y permanente el derecho de cada uno (II-II, q. 58, a. 1). Es, siempre, una virtud alteritaria, siempre hace referencia a otra persona, relaciona a una persona con otra y lleva a reconocer y dar el derecho que a ella le corresponde (a. 2). Sus especies son dadas por diferentes objetos formales, pues el derecho debido puede ser el propio de la comunidad (justicia legal o social) o el propio de un individuo (justicia particular). En este último caso aparecen dos nuevas especies, en la medida en que la razón puede llevar al individuo a dar lo que les corresponde a otros individuos en tanto que individuos (justicia conmutativa) o bien aquello que se les debe en tanto que miembros de la comunidad (justicia distributiva).

Diferentes especies de justicia surgidas, ante todo, del hecho de que "el bien común de la ciudad y el bien singular de una persona no difieren solamente según lo mucho o lo poco, sino según diferencia formal; pues una es la razón del bien común y otra la del bien singular, lo mismo que se distingue el todo y la parte" (II-II, q. 58, a. 7, ad 1). En segundo

${ }^{8}$ Jaime Ruiz de Santiago, Naturaleza y fines del derecho, 1978, México, UIA. 
lugar, la búsqueda de lo debido a una "parte" social genera una distinción, pues "toda parte puede ser considerada en un doble aspecto: uno, en la relación de parte a parte, al que corresponde en la vida social el orden de una persona privada a otra, y este orden es dirigido por la justicia conmutativa, consistente en los intercambios que mutuamente se realizan entre dos personas. Otro es el del todo respecto a las partes, y a esta relación se asimila el orden existente entre la comunidad y cada una de las personas singulares; este orden es dirigido por la justicia distributiva" (II-II, q. 61, a. 1). Estas especies de justicia -legal, conmutativa y distributiva - se realizan según criterios distintos y dan lugar, por su corrupción, a vicios diferentes.

El tratamiento de las especies de justicia - con sus vicios opuestosva de la II-II, q. 61 hasta la 78. La materia que se estudia entre la q. 57 (a partir del objeto de la justicia) y la q. 78 (que trata de la usura en los préstamos) constituye lo propio de los famosos tratados De Iure et Iustitia (Del derecho y la justicia).

La q. 79 habla de las partes cuasi integrales de la justicia, y establece que estas permiten hacer el bien y evitar el mal con relación a la justicia propia, es decir, en materia de lo que es debido estrictamente. Las especies de justicia constituyen lo debido a otro, sociedad o persona singular, en tanto que las partes cuasi integrales de la justicia conservan lo previamente constituido. "En este terreno una cosa es establecer la igualdad y otra no destruirla una vez instaurada" (II-II. q. 79, a. 1, ad 1).

Con la q. 80 se inicia el estudio de las partes potenciales de la justicia, que continúa hasta la q. $120 .{ }^{9}$ Estas cuestiones no forman parte de la unidad De Iure et Iustitia por una simple razón: debido a que la justicia implica realidades debidas posibles de ser entregadas y exigidas, y hay ocasiones en que o bien es imposible de pagar una deuda o bien es imposible hacer compulsorio su cumplimiento. En ambos supuestos, falla lo propio de la justicia estricta.

${ }^{9}$ Suma Teológica, 1955, Madrid, BAC, vol. IX. El volumen contiene las qq. 80-140. 
Aparece entonces el estudio de las partes potenciales de la justicia que, como ya dijimos, nos coloca ante una verdadera ramificación de la misma.

El estudio de las qq. 80 a 120 da origen a dos consideraciones diversas, según exista una deuda rigurosa, pero con desigualdad en el pago debido a que lo estrictamente debido es imposible de dar (qq. 80 a 105), porque es posible dar lo debido sin existir la posibilidad de exigirlo de manera rigurosa (qq. 106 a 119). La q. 120 mira, al contrario de las anteriores, a la deficiencia en la deuda de la justicia legal.

Por consiguiente, hay una diferencia con relación a la naturaleza de la obligación que se genera, pues mientras la justicia rigurosa (qq. 57-78) genera obligaciones "legales" — con apoyo en la ley positiva-, la deficiencia en la justicia (qq. 80-120) hace aparecer obligaciones puramente morales, con apoyo exclusivo en la ley natural.

De cualquier modo, las partes potenciales de la justicia abarcan dos campos, según que la virtud nos lleve a dar a otro lo debido pero "sin que podamos entregar la exacta equivalencia. El primero comprende todo aquello que el hombre da a Dios porque se le debe, y, sin embargo, no puede lograr la igualdad, es decir, devolverle tanta como le debe [...]. En segundo lugar, no es posible devolver a los padres en estricta igualdad lo que se les debe [...]. Y en tercer término, el hombre no puede dar a la virtud una recompensa que sea equivalente" (II-II, q. 80, a. 1). Esto genera las correspondientes virtudes de religión, de piedad y de veneración u "observancia". De estas virtudes potenciales la religión merece un tratamiento más amplio, que se realiza entre las qq. 81 y 100. Ahí se establece su naturaleza en tanto que virtud (q. 81), sus actos propios (qq. 82-91) tales como la devoción, la oración el sacrificio, la alabanza, etc., y los vicios que aparecen como opuestos (qq. 92-100), tales como la idolatría, la adivinación, el sacrilegio, etcétera.

La piedad (q. 101) lleva al cumplimiento de lo debido principalmente a los padres, lo que se resume fundamentalmente en actitudes de obediencia y respeto. El respeto u observancia (q. 102) regula los actos debidos a "personas constituidas en dignidad" (a. 1), es decir hacia quienes cumplen el difícil cargo de gobierno y dirección. A ellos 
se les debe honor (q. 103) y obediencia (q. 104). Esta última cuestión, como aquella en la que se analiza el vicio contrario, es decir la desobediencia (q. 105), contiene reflexiones de enorme interés para nuestros tiempos. Con ello termina el tratamiento de las partes potenciales de la virtud que implican la existencia de una deuda de imposible equivalencia en su pago.

Existe, sin embargo, un segundo campo de las partes potenciales de la justicia, que aparece cuando es posible el pago equivalente pero la deuda en sí misma no es rigurosa. Se trata, en consecuencia, de obligaciones morales o naturales (según la terminología contemporánea propia de las obligaciones de derecho positivo). En estas cuestiones (106-119) se introduce una nueva distinción, pues el defecto de la razón de débito, propio de la justicia, puede considerarse en atención a una de las dos clases de débito: moral y legal, según las cuales Aristóteles distingue dos especies de derecho o justo. Débito legal es el que estamos obligados a cumplir por imposición de la ley, constituyendo el objeto propio de la justicia, virtud principal. Débito moral es lo que uno debe por honestidad de la virtud. Mas, como la noción de deuda entraña necesidad, de ahí que ese débito moral tenga dos grados: uno que de tal manera sea necesario que no resulte posible conservar sin ello la honestidad de las costumbres; en este grado hay más estricta razón de deuda, y puede considerarse desde diversos puntos de vista. Primero, por parte del mismo deudor, y entonces consiste en que el ser humano se muestra a los demás en sus palabras y en sus obras tal cual es; de ahí que a la justicia se agregue la "veracidad", por la cual, en frase de Cicerón, "se expresan fielmente las cosas que son, han sido o serán". Puede también considerarse por parte de aquel a quien algo se debe; esto es, cuando se recompensa a una persona con arreglo a lo que hizo. Unas veces se trata de bienes, y entonces se añade a la justicia la "gratitud", otras veces se trata de males, y entonces se añade la "vindicación".

"Hay un segundo grado de débito: lo que es necesario porque conduce a una mayor honestidad moral sin ser indispensable a la conservación de lo honesto; y a este débito se refiere la "liberalidad", la "afabilidad o amistad" y otras virtudes semejantes" (q. 80, a. 1). 
Con ello nos aproximamos a las virtudes que nos interesan en la presente investigación. El texto en el cual se centra nuestra reflexión se refiere a deudas morales (requeridas tan solo por la honestidad de la virtud), que pueden ser "apremiantes" o necesarias para la conservación de una vida honesta o "no apremiantes" o "no indispensables" para este fin.

Las indispensables para la consecución de la honestidad de las costumbres pueden mirar al acreedor (qq. 106-108) o al deudor (qq. 109-113). Las no indispensables pero aconsejables son estudiadas en las qq. 114 a 119 y representan perfecciones que hacen más humana y excelente la convivencia humana pero que no son necesarias para que esta se realice. Apremiante para el acreedor, si ha recibido un beneficio, es la gratitud (q. 106), que tiene como vicio principal la ingratitud (q. 107), la que aparece como defecto de la anterior; si ha recibido un mal, es la venganza (q. 108) o castigo.

Se inicia entonces el tratamiento de aquellas virtudes — siempre partes potenciales de la justicia - que son necesarias en un sujeto para que pueda existir una "honestidad de las costumbres" o bien para aumentarla. Las primeras (qq. 109-113) aparecen con un carácter urgente o "apremiante", en tanto que las segundas (qq. 114-119) no lo son. Ambas, sin embargo, son requeridas en un sujeto para que se logre o aumente la perfección de la vida del ser humano en sociedad. Estas últimas son precisamente las virtudes que nos interesa comprender con mayor detenimiento.

\section{Naturaleza de la veracidad, de la afabilidad y de la liberalidad}

Al tratar este punto Santo Tomás, como en muchas otras cuestiones, se aparta de Aristóteles y va mucho más lejos. Su originalidad se muestra en el hecho de que no se limita a agrupar el mundo de las virtudes morales en torno a esas perfecciones principales que son las virtudes cardinales, sino también a considerar que la perfección social, alteri- 
taria, no se consigue con la instauración exclusiva de la justicia en tanto virtud cardinal, sino que implica y supone el logro de ciertas perfecciones que van más allá de la justicia estricta pero que se requieren para que la sociedad humana sea en verdad humana. Ello es lo que indica la presencia de virtudes tales como la gratitud, la veracidad, la afabilidad, la liberalidad y otras.

Aristóteles había considerado que estas virtudes eran de naturaleza moral, pero les asignaba el perfeccionamiento de otros apetitos que no eran el racional (voluntad). Así pensaba, por ejemplo, que la liberalidad perfecciona al apetito concupiscible y se refiere a los afectos de la riqueza, análogos - pensaba el Estagirita - a aquellos del tacto que son rectificados por la templanza, al igual que la afabilidad y la veracidad, con la diferencia de que la primera regula los placeres propios del trato agradable y la segunda el amor a la verdad.

Santo Tomás, por el contrario, piensa que esas virtudes perfeccionan al apetito racional (a la voluntad) y que son, en consecuencia, partes de la justicia. Se trata de partes no subjetivas sino potenciales, pero están implicadas por la perfección total de la justicia, y en consecuencia, son requeridas por la excelencia de la vida en sociedad. Ello significa, como ya señalamos, que la vida social descansa en el logro de la justicia, pero implica otras virtudes que van más allá de la atribución de aquello que es debido a los demás de manera perfecta y conforme a obligaciones estrictamente exigibles a través de la ley positiva.

No puede haber perfección social — esto es claro — sin la atribución de aquello que es riguroso y estrictamente exigido por el bien particular de otras personas y por el bien común de la sociedad, pero esa perfección requiere también la presencia, en el seno de la vida social, de otras virtudes tales como la veracidad, la liberalidad, la afabilidad, etc. Esas virtudes son parte de la justicia, en el sentido más pleno y verdadero de la expresión.

Ello nos permite comprender hasta qué punto la doctrina del Angélico es profundamente humana y realista, de qué manera considera las dimensiones totales e íntegras de la persona humana: la perfección de la 
justicia no se logra tan solo cuando se da a cada uno lo que le es estrictamente debido y puede ser rigurosamente exigido. Hay realidades que son debidas pero que no pueden ser objeto de una norma positiva coercitiva. De nuevo, las tesis del positivismo jurídico se manifiestan como insuficientes para explicar la complejidad de lo real.

Tan compleja es la vida social que Santo Tomás introdujo una nueva distinción al hablar de virtudes que responden a una deuda no rigurosa (no legal) pero necesarias para la "honestidad de las costumbres" y de otras que no lo son. No aparecen como indispensables, pero sí como requeridas para la obtención de la plena perfección social.

La plenitud en la vida social implica, además de cumplir con lo rigurosamente debido, que la persona humana "sea transparente" con los demás y estos tienen el derecho — no legal, sí natural— de recibir una comunicación verídica de lo que es ella, tienen el derecho a que la persona les trate con humanidad ("con el corazón en la mano") y se muestre igualmente humano en el uso de las riquezas.

Recuerda uno, con una aplicación diferente, aquella reflexión de Jacques Maritain según la cual lo que el mundo requiere son personas "con el espíritu duro y el corazón suave". Una sociedad cuyos miembros solo se limitan a dar lo rigurosamente debido y exigible merecería el calificativo de justa pero también de "fría e inhumana"; y si no dan lo rigurosamente debido y exigible, difícilmente se podría establecer una real veracidad, afabilidad, etc. y tal sociedad sería considerada como hipócrita. Solo cumpliendo con lo rigurosamente debido, perfeccionado con la transparencia de uno mismo, un trato afable y un uso racional de las propias riquezas, solo así, repito, las personas podrán construir una sociedad verdadera y plenamente humana, justa y cálida. La perfección del amor se encontrará ya anunciada. O más bien: el amor, que incluye como primer elemento el cumplimiento de la justicia, estará posibilitado para mostrar su riqueza más propia y original, que es aquella gracias a la cual el sujeto actúa como manifestación de la propia perfección, no respondiendo tan solo a lo debido en justicia, sino manifestando su calidad amorosa.

Piensa Santo Tomás que si entre la veracidad, la afabilidad y la liberalidad hay la semejanza de que todas ellas rebasan los límites de lo 
justo exigible, sin embargo les separa una fuerte diferencia, pues mientras la veracidad es una virtud indispensable para la humana convivencia, la liberalidad y la afabilidad no lo son. La veracidad posee, en este sentido, un carácter apremiante que no poseen las dos restantes: estas, aunque necesarias para una vida social honesta, no resultan indispensables. Su ausencia implicará, en el caso de la veracidad, la destrucción misma de la sociedad, en tanto que la ausencia de la liberalidad y de la afabilidad explicará una convivencia social dura e imperfecta.

Es así como la veracidad posee una importancia primordial, pues sin ella desaparece la posibilidad de que exista una verdadera sociedad humana, de modo que su carencia dará lugar a una doble posible situación: que las personas "se cierren en sí mismas" y que, en tendencia centrífuga, tiendan a separarse del conglomerado social, pensando que ahí la vida es imposible, o bien que, para evitar tal dispersión, se recurra a la fuerza, a la violencia y a la opresión para mantener a los seres humanos aparentemente unidos. Esta segunda posibilidad es la que se presenta en los regímenes totalitarios que pretenden hacer válida la ficción de un organismo social cuya cohesión no le viene del interior — de una vida en la virtud — , sino totalmente del exterior — del miedo, la amenaza y la coacción-. Lo mismo acontece en aquellas sociedades, no raras en nuestros días, que quieren legitimar su existencia solamente en el dar garantía de seguridad a sus miembros... produciendo aquello que se presenta como causa de miedo e inseguridad. ${ }^{10}$

La veracidad es la verdad que el ser humano hace existir en sus relaciones sociales a fin de construir la verdad de estas. Así, advierte el Angélico que la verdad guarda dos significados, pues existe la "verdad en sí", según la cual algo es dicho "verdadero", ya sea porque el objeto se conforma a su regla (verdad ontológica) o bien porque el juicio se conforma a su regla propia, que es lo real (verdad lógica). En ninguno de estos casos se abre la posibilidad a la verdad como virtud. Pero también, segundo significado, existe "la verdad que se dice", y es entonces gracias a ella que una persona humana se dice "ser verdadera", "ser veraz" o "ser verídica". Solo se puede ser verídico si se dice la verdad y absurdo sería pensar o decir lo contrario.

${ }^{10}$ Véase especialmente Zygmunt Bauman, Confianza y temor en la ciudad. Vivir con extranjeros, 2009, Barcelona, Arcadia. 
Por la veracidad (literalmente: “decir la verdad") la persona expresa el mundo de su interioridad, revela sus pensamientos y sentimientos más profundos, se entrega a los demás, se da a los otros. De ahí la seriedad que tiene la expresión verídica ("que dice la verdad") y la trascendencia que posee: lo más profundo, íntimo, de las personas se manifiesta a los demás, y estos deben ser conscientes que tal manifestación responde a un movimiento gratuito y generoso, de modo que debe ser recibido con gratitud y correspondido de la misma manera.

La revelación de la interioridad personal puede realizarse con diversas "intenciones": para lograr una pura y libre manifestación del sujeto, para buscar comunicación con los otros, para producir un acuerdo y un compromiso con los demás, etc. Todo ello poseerá el carácter sagrado que se deriva de la dignidad propia de la persona. Por ello nadie debe escuchar con ligereza (ni, lo que sería aún peor, con desprecio) la manifestación de una tristeza, de un dolor o de un amor, del mismo modo que se comprende la excelencia del entendimiento humano, de la intercomunicación y el carácter trascendente de cualquier compromiso. En este sentido, el mismo Cicerón apuntaba que "fundamento de la justicia es la fe, es decir, la constancia y la sinceridad en mantener las cosas dichas y convenidas". ${ }^{11}$ Esto es válido no solo para los individuos, sino también para los Estados: la norma fundamental de la vida internacional, que hace posible la relación entre los diversos sujetos del Derecho Internacional, es pacta sunt servanda ("deben cumplirse los compromisos"), que lleva a tomar en serio a quien se compromete y a cumplir de buena fe una obligación libremente contraída.

Si las personas no expresan lo que piensan, si no es digna de crédito su palabra, si no merece ser creído su discurso, si sus compromisos no son dignos de ser creídos y aceptados, la vida social — de cualquier sociedad, incluida la misma internacional - se vuelve radicalmente imposible. De ahí la importancia de la veracidad, pero también la enorme extensión que comprende, pues es fácil entender que si la persona normalmente se revela a través de la palabra, puede también

${ }^{11}$ Cicerón, De los Deberes, 1, 7, 4, 1962, México, UnAM, versión de Baldomero Estrada Morán. 
hacerlo a través de otros medios: gestos, actitudes o conductas, porque todas estas expresiones de la persona humana se encuentran sometidas a la voluntad, la veracidad es una virtud moral.

La veracidad no es una virtud intelectual ni teologal, sino estrictamente moral, porque perfecciona la voluntad y la lleva a decir lo que el sujeto piensa. Es la expresión que usa de la palabra (o de su ausencia), de los gestos, de las conductas, etc., a través de la cual la persona se revela. Por ello, puede decirse que la veracidad es la verdad moral, diferente de la ontológica y de la lógica, y que es ella la que más compromete a la persona.

Quizá se pueda pensar que nuestra época, por otra parte, es especialmente sensible a esta especie de verdad y que es exigente en lo que mira al carácter totalizador de la expresión verídica, pues es atenta a la armonía entre lo que se dice y aquello que se actúa. Esto es, sin lugar a dudas, muy valioso y consecuente, pues no se puede pretender "ser veraz" en la palabra y "ser mentiroso" en la conducta.

Una precisión de interés es la que se realiza en la respuesta a una de las objeciones a la cuestión 109, referente a la veracidad, en la que se señala que esta virtud moral

ocupa el medio entre el exceso y el defecto de dos modos. Uno, respecto del objeto, porque la veracidad en su misma naturaleza implica una cierta igualdad, que es el justo medio entre lo más y lo menos. Así, quien dice la verdad de sí mismo ocupa el punto medio entre el que exagera y el que mengua tal verdad. Otro sentido es respecto del acto mismo, en cuanto dice la verdad cuando y según convenga. En este caso el exceso se da al hablar de sí mismo cuando no debía hacerlo, y el defecto, en callar cuando lo debía hacer. [q. 109, a. 1, ad.3]

Con este rico párrafo se abren las ulteriores reflexiones. En ellas se señala que la veracidad es una virtud especial que establece, como toda virtud, un orden determinado, en este caso el orden de las palabras y de las acciones en conformidad con la realidad que ellas expresan, es decir, lo que la persona humana piensa. 
Que la veracidad sea una virtud parte de la justicia, se muestra ante todo en su carácter alteritario, pues nos permite expresar, mediante palabras o acciones, nuestro pensamiento a otro ser humano, $y$, en segundo lugar, por establecer una equivalencia entre el pensamiento y sus signos. Que sea parte potencial se muestra porque el débito que regula no es un débito legal, sino puramente moral, de modo que, aunque los miembros de una sociedad tienen derecho a que se les hable con verdad, este derecho no puede ser requerido a través de la vía legal. Que uno exprese lo que en verdad piensa es exigencia de la justicia, más de una "justicia moral" que no por no ser "legal" deja de ser en extremo apremiante.

Esta virtud, como se ha indicado, cubre dos grandes zonas, pues el pensamiento se puede expresar a través de la palabra o de las acciones, $\mathrm{y}$, en ciertas circunstancias, mediante sus respectivas ausencias, que para poseer una dimensión moral deberán poseer la naturaleza de auténticas privaciones, de donde los vicios que se le oponen por exceso y por defecto se establecen también en ambas zonas. A la verdad del pensamiento reflejada en la palabra se opone la mentira; la simulación se opone a la verdad encarnada en las acciones. A la veracidad se opone por exceso la jactancia, en tanto que la denominada "ironía" la contraría por defecto.

El tratamiento que hace Santo Tomás de la mentira en la q. 110 posee gran finura y aporta una comprensión esclarecedora del punto. A partir de un texto de San Agustín, en el que se sostiene que "no hay duda de que miente el que enuncia algo falso con intención de engañar, por lo cual es patente que el enunciado de algo falso con voluntad de engañar a otro es mentiroso", ${ }^{12}$ se afirma que el comparar es obra propia de la razón (omnis repraesentatio consistit in quadam collatione, quae proprie pertinet ad rationem), de modo tal que el enunciado de un pensamiento solo será moral en la medida en que sea voluntariamente querido por la voluntad. Esta, la voluntad, puede buscar la adecuación entre lo pensado y lo expresado o, por el contrario, puede romper tal adecuación.

${ }^{12}$ De Mend., c. 3, cit. en Suma Teológica, q. 110, a.1. 
A esta consideración, que es la más formal del tema, se añaden dos aclaraciones: una, que el pensamiento es verdadero si se adecua con lo real o falso si no se adecua; y la segunda, que el sujeto, al decir lo contrario de lo que piensa, puede tener la intención de inducir a engaño a su interlocutor.

Por ello, es necesario distinguir: el juicio puede ser verdadero o falso; la expresión, veraz o mentirosa; la intención, dolosa o no dolosa. El juicio falso implica una falsedad material; la mentira formal es la afirmación de lo contrario de lo que se piensa y se constituye en dolosa si lleva además la intención de engañar. De donde, "si uno expresa algo falso, pero creyendo que es verdadero, es una falsedad material, no formal, porque no es proferida con intención. No alcanza, pues, la razón formal de mentira, porque lo no intencionado es meramente accidental y no puede constituir diferencias específicas" (q. 110, a. 1).

La mentira, así, no se confunde con la falsedad. Ello explica que lo contrario de la verdad sea la falsedad, en tanto que la mentira no se opone a la verdad, sino a la veracidad. En otras palabras: la verdad — la adecuación entre lo que se piensa y lo que existe - no posee un carácter moral, en tanto que la veracidad y la mentira sí lo tienen. Por ello el texto continúa: "Si uno dice una falsedad formal con intención y conciencia de mentir, aunque en sí sea verdad, tal acto, desde el punto de vista de la voluntad y de la moralidad, contiene en sí mismo la falsedad y solo accidentalmente la verdad. Pertenece, por ello, a la especie de mentira".

Así se explica ese extraño fenómeno de que alguien pueda ser mentiroso y decir, sin embargo, la verdad. Lo formal de la mentira es el decir lo contrario de lo que se piensa. Si lo que se piensa es falso (por no adecuarse a lo existente), se dirá algo que es verdadero, pero el sujeto será un mentiroso.

La intención de engañar "es una cierta consecuencia de la mentira" y es paradójico que, si aquello que se piensa es falso, el sujeto dirá algo verdadero (materialmente) y su intención de engañar le llevará a producir un conocimiento verdadero siendo él mentiroso. ¡Ironías de la vida humana! 
Por ello, en la respuesta a la primera objeción se sostiene que "es más opuesto a la veracidad, en tanto virtud moral, el decir algo verdadero con intención de decir falso que el decir algo en sí falso con idea de decir la verdad". Y es que lo esencial a la mentira es la inadecuación voluntariamente querida de la expresión con el entendimiento. Esto trae como consecuencia el que estar en la falsedad - en el error - no sea algo propiamente moral, a menos de ser voluntariamente buscado, en tanto que la mentira siempre lo es.

Claro que pensar con verdad es importante, pero para el mundo moral lo es más el decir lo que se piensa. Y no por decir algo falso se es mentiroso. Pensar lo contrario sería, al menos, equivocado.

Interesa esta enseñanza por sus implicaciones: el investigar la falsedad o la verdad de una doctrina no significa poner en tela de juicio la "buena o mala voluntad" de su defensor, y una cosa es pronunciarse en torno a tal falsedad (o verdad) y otra, muy distinta, juzgar de falta (o mérito) moral a su autor. ¡El juicio que de errónea pueda tener una doctrina no significa condena de su defensor! Es tan íntimo y profundo el mundo moral que se puede decir algo "materialmente" verdadero y, sin embargo, ser moralmente mentiroso.

En este terreno es necesario tener ideas muy claras, pues se corre el riesgo de condenar al error y a la persona que lo sostiene, por pensar que es una persona mentirosa. Mas ello también implica otra consecuencia de interés en los actuales momentos, en los que se suele ser en extremo benigno con las mentiras "que persiguen un fin bueno", mentiras llamadas "piadosas" o "blancas", realizadas con "buena intención”.

La mentira es formalmente condenable por la falta de proporción entre el pensar y su expresión. Es esto siempre condenable, en la medida en que es conocido y buscado. Ninguna "buena intención" puede salvar lo que es malo ex genere. Y a este respecto se repite una doctrina rica en virtualidades: para que algo sea bueno es necesario que todos sus elementos lo sean. Bonum est ex integra causa, malum autem ex singularibus defectibus (I-II, q. 18, a. 4). El bien es más exigente que el mal moral, pues mientras que el primero requiere la integridad de todos los elementos que entran en juego en la acción humana (objeto, 
circunstancias, intención o fin), el mal aparece por el defecto de cualquiera de ellos. La mentira es condenable porque la persona, de manera consciente y querida, busca romper la armonía, el orden, entre lo que se piensa y lo que se expresa. Este desorden radical (formal) existe en cualquier clase de mentira e imposibilita que pueda ser considerada como buena y ordenada. En otras palabras: la mentira no es un mal moral por el daño que causa, sino por el desorden que implica. De nuevo es evidente que el bien moral es diferente del bien metafísico o del natural.

En todo caso, la mentira implica siempre un decir. Se puede, por el contrario, actuar voluntariamente en sentido contrario al que se piensa. Pero este no es más el mundo de la mentira sino de la simulación, que no es otra cosa sino una mentira actuada. Y una especie de simulación es la hipocresía, a través de la cual el agente busca manifestarse por quien no es: se simula una personalidad diferente a la que realmente se posee.

Al hablar en la q. 111 de esa forma de simulación que es la hipocresía, Santo Tomás cita dos textos interesantes. Uno de ellos, de San Isidoro de Sevilla, quien en sus Etimologías escribe que "el nombre de hipócrita se tomó de los cómicos, que trabajan en el escenario con el rostro cubierto por una careta, que les da distintas expresiones para producir en el público la ilusión del propio personaje que representan, hombre o mujer"13; el otro, de San Agustín, quien en el mismo sentido dice que "como los comediantes (hipócritas), cuando fingen otros personajes, hacen el papel de otros distintos de ellos mismos (porque quien representa el papel de Agamenón no es él realmente, sino quien lo finge), así también, en la vida religiosa y civil, quien pretende aparentar lo que no es, es un hipócrita: finge obrar la justicia, pero no la guarda". ${ }^{14}$

Mentira y simulación suponen siempre una falta de orden, de adecuación, entre lo que se piensa y lo que se dice o actúa. En eso reside, como ya se indicó, su malicia, aunque el sujeto lo pueda realizar con una intención encomiable.

${ }^{13}$ Etimologías, L. 10 ad litt; cit. en Suma Teológica, q. 111, a.2.

${ }^{14}$ De serm Dom. in Monte, 1. 2, c. 2, cit. en loc. cit. 
Diferentes de esos vicios aparecen la jactancia y la "ironía”, como opuestos a la veracidad por exceso y por defecto. La jactancia implica que el sujeto se atribuye perfecciones que no posee y que lo colocan sobre los demás. Es diferente de la vanagloria en la medida en que, mientras esta última no supone mentira, la jactancia sí. Este vicio, la jactancia, nace de la soberbia. "En efecto, el que se arroga interiormente una superioridad ficticia, hace ostentación externa de cualidades mayores de las que tiene" (q. 111, a. 1, ad 2).

Lo que se denomina "ironía" aparece por un elemento diferente y opuesto a aquel que permite la jactancia, pues mientras esta implica un creerse y decirse más de lo que se es, la "ironía" se produce por creerse y decirse menos de lo que en verdad se es. Se podría pensar que no hay defecto cuando alguien dice ser menos de lo que piensa ser, afirma tener menos perfecciones de las que realmente piensa, para evitar la soberbia, pero en la respuesta a la objeción tres del artículo uno (q. 112) se dice que "nadie debe cometer un pecado para evitar otro. Por lo mismo, no se debe mentir de ningún modo para evitar la soberbia". Y se recuerda a San Agustín, quien señala que "es una humildad imprudente la que se expone a mentir".

El tema es delicado, pues hay "falsas humildades" (ironías) que pueden nacer de reales soberbias. El corazón humano es tan complicado que puede empujar a un sujeto a deleitarse exageradamente (soberbia) en perfecciones que posee (vanagloria) o que no posee (jactancia) usando el recurso de denigrarse conscientemente, sabiendo que en los demás esto producirá un efecto opuesto.

Mas, ¿qué pensar de quienes, excelsos en virtudes cristianas, como Sta. Teresa de Jesús o el P. de Foucauld, que se confiesan como los mayores pecadores de la tierra, o admirables en sabiduría teológica, como el mismo Santo Tomás de Aquino, quien señalaba que su magna obra era como paja que merecería ser quemada, o extremadamente poseedores de sabiduría filosófica, como el mismo Sócrates, quien sostenía no saber nada? ¿Puede acaso pensarse que ellos, para evitar la soberbia, caían en la "ironía", en una "falsa modestia" o en "falsas humildades"? Ciertamente, no. 
Esto requiere ser explicado. Parece que tal explicación se encuentra en una doble razón: ante todo en el hecho de que, como se ha señalado, no es mentira decir aquello que es falso pero se piensa verdadero, de modo que no se puede admitir que exista "ironía", o como se le quiera llamar, si el sujeto cree y se piensa pecador, vil, despreciable o ignorante.

La segunda razón requiere profundizar lo afirmado: ¿cómo es posible que un santo se piense pecador, que se sienta "con las manos vacías" quien se ha consumado en la entrega a los demás, que se experimente como ignorante quien tanto ha permitido avanzar al conocimiento humano? Parece que la respuesta no es difícil de encontrar: simplemente ese sujeto se compara con el valor al que incesantemente ha tendido en su existencia y de cuyas exigencias él es más consciente que nadie. Y, en comparación con tal valor, se da cuenta de las limitaciones, traiciones y olvidos que él mismo ha mostrado en su conducta. Nunca el ser humano es más consciente de su imperfección que cuando ha estado en presencia de aquel cuyo nombre es santo y ante quien los ángeles mismos se deben cubrir el rostro; nunca es más realista con respecto a su ignorancia que quien ha logrado asomarse a los límites infinitos de la sabiduría. Al ascender una montaña el horizonte no se empequeñece, sino que por el contrario se amplía.

Es, en el fondo, la experiencia que caracteriza al profeta, al místico, al sabio o al santo. Tal experiencia los conduce a una verdadera humildad al confesar las imperfecciones que experimentan y de las cuales poseen plena y total lucidez. Pero el peligro ciertamente existe, al confundir lo que es humildad profunda con aquello que es soberbia disfrazada. ¡Qué distancia infinita existe entre las Confesiones de San Agustín y las de Juan Jacobo Rousseau!

Si se quiere, se puede recordar la famosa parábola del fariseo y del publicano que entraron a orar al templo. El primero es la encarnación misma de la soberbia, que se deleita en las perfecciones que realmente posee (vanagloria); el segundo confiesa su pecado y se abre a la Divina Misericordia. Solo el segundo salió perdonado.

Es toda una tipología de actitudes morales la que se necesita en este punto y que tiene como materia los secretos profundos del corazón 
humano. En el vértice se encuentra la del ser humano que se enfrenta al Absoluto, percibe su propia miseria pero se entrega confiado a quien reconoce como Misericordia Infinita.

Por su importancia, la veracidad, con los vicios que se le oponen, es tratada a lo largo de cinco cuestiones (109-113). Sin ella es imposible la vida en sociedad.

La afabilidad y la liberalidad, aunque de gran trascendencia, no aparecen como indispensables. La primera, la afabilidad, nos lleva a tratar de "manera decorosa" a los demás, en nuestros modales exteriores y a través de las palabras. Al no implicar el mundo de los afectos, la afabilidad no necesariamente es muestra de perfecta amistad (q. 114, a. 1, ad 1), pero sí de justicia. Creo que también se puede traducir el día de hoy como "gentileza". ${ }^{15}$

Por esta perfección la persona "se ordena debidamente” a los demás. Aparece como "la decente convivencia con los demás, compañeros nuestros en virtud del amor común que nos une a nuestros semejantes" (q. 114, a. 1) y, como se comprende fácilmente, no repugna sino que corona a la veracidad, expresada en palabras y acciones. Hay que hacer notar que la afabilidad, la amabilidad o buen trato con los demás es una virtud mencionada por San Pablo en la Carta a los Filipenses (4, 4-5), cuando, recomendando a los miembros de la comunidad estar alegres, el Apóstol explica cómo dar testimonio de esta alegría, de este gozo, que debe estar siempre presente a fin de hacerlo creíble. "Que vuestra afabilidad — escribe — sea clara para todos los hombres." 16

${ }^{15}$ Esta importante virtud ha sido también analizada por Henri Bergson en su ensayo $L a$ politesse, que fue originalmente un discurso pronunciado por el pensador en 1892 en una ceremonia de entrega de premios en el Liceo Henri IV. Ahí afirma que la "gentileza" es "cierto arte de testimoniar a cada persona, a través de actitudes y palabras, la estima y la consideración a las cuales tiene derecho" (2008, París, Payot, p. 21). Gracias a ella, las personas son llevadas "a conocerse y amarse mejor las unas a las otras" (p. 31).

${ }^{16}$ Como observa el P. Raniero Cantalamessa en su bello libro Contemplando la Trinidad, "la palabra 'afabilidad' traduce un término griego (epieikes) que indica todo un conjunto de actitudes, que incluye la clemencia, la indulgencia, capacidad de ceder, no ser terco [...]. Los cristianos manifiestan la alegría cuando, evitando toda acritud y resentimientos inútiles en el diálogo con el mundo o entre sí, saben irradiar confianza y esperanza”.

"El feliz no es resentido, rudo, no siente la necesidad de puntualizar todo y a todas horas, sabe relativizar las cosas, porque conoce algo mucho más grande; ama porque se siente amado." (2006, Burgos, Monte Carmelo, p. 39) 
La justicia requiere no solo que expresemos "con transparencia" nuestros pensamientos (veracidad) sino que también "transparentemos" el respeto que todos los otros integrantes de la sociedad nos merecen por participar de nuestra misma naturaleza (afabilidad). Esto vale para todas las sociedades, desde la más pequeña hasta la más universal.

Faltaría gravemente a la verdad quien considerase que el expresar con claridad los pensamientos - lo que en muchos medios se conoce como "autenticidad" - no puede más que ir acompañado de una conducta grosera y poco cordial.

Con ello se percibe que a la afabilidad, el modo amable de tratar a los demás, se oponen los vicios contrarios, surgidos por la posibilidad de excederse en la afabilidad (adulación) o mostrarse ausente de la misma (litigio). De la primera, de la adulación, se dice que

la afabilidad, aunque tiene por objeto propio el agradar a quienes lo rodean, sin embargo no debe temer, en caso necesario, desagradar por conseguir un nuevo bien o por evitar un mal. Y si uno quiere agradar siempre, se excede en afabilidad, y peca por exceso. Si busca algún beneficio se le llama "adulación". Sin embargo, el nombre de adulación se extiende comúnmente a todos aquellos que de manera desmedida buscan agradar a otros con palabras o con hechos en el trato corriente. [q. 115, a. 1]

En esta reflexión el P. Cantalamessa observa que el término "afabilidad" (epieikes) es el mismo término del cual deriva la palabra epikeia, usada en el Derecho y con relación a la justicia.

Como se sabe, la epikeia (que hoy se traduce como "equidad") es una virtud moral, íntimamente relacionada con la justicia, gracias a la cual una persona, en violación de lo que dice una norma dictada por la autoridad, obra precisamente lo contrario a fin de realizar el espíritu de justicia que debe animar ese ordenamiento. Esta virtud de la epikeia es fundamental y se explica por el hecho de que la realidad existencial es siempre más rica que todo aquello que pueda prever un ordenamiento. Cierto que este debe tener siempre un carácter general, pero le es imposible considerar todas las posibles realizaciones que se dan en la realidad concreta. Gracias a la epikeia el sujeto se sabe "ajustar" a esos caracteres singulares y concretos, no previstos por la norma, que le llevan a actuar "en contra de lo que dice la norma" a fin de realizar la justicia y el bien común que deben animar al ordenamiento en cuestión.

La epikeia revela un derecho superior que hace perder al ordenamiento su carácter obligatorio. Santo Tomás ve en la epikeia la virtud moral, dictada por la prudencia, que regula la aplicación de la norma contra sus propios términos y crea entonces una verdadera excepción o excusa (II-II, q. 120, a. 2). 
La vida social se encuentra ordenada por la justicia, lo que no es siempre fácil ni agradable. Se podría decir que la justicia respecto de los demás lleva a tratarlos siempre con verdad, la que "no debe temer desagradar" para lograr un bien o evitar un posible mal.

El litigio tiene un sentido opuesto: este vicio lleva a contradecir las palabras de otro tan solo por el placer de entristecer, de apenar, de "contristar" y tal es precisamente su intención. El litigio, si se compara con la adulación, aparece como un vicio más grave pero menos torpe, y esto debido al desprecio hacia los demás, que aparece como su origen. $\mathrm{Y}$ es que

no siempre coincide en los actos humanos lo más grave con lo más torpe. El pudor le viene al ser humano de la razón y, por tanto, son más torpes los pecados carnales, en los cuales la carne domina a la razón; pero tienen más gravedad los pecados espirituales, porque denotan un mayor desprecio. Igualmente, los pecados con engaño son más torpes, en cuanto parecen proceden de una cierta debilidad y de una falsedad de la razón; pero los pecados manifiestos denotan un mayor desprecio. [q. 116, a. 2, ad 2]

Por ello, la adulación revela una mayor torpeza, pero el litigio posee una mayor gravedad.

Es así como la justicia, con todas sus consecuencias, requiere la diafanidad de nuestro interior (veracidad) y el trato decente y amable con los demás (afabilidad). También precisa que los bienes de los cuales se usa — en especial el dinero - sean manejados con orden y racionalidad.

A causa de ello, la justicia requiere de la liberalidad, virtud que permite usar convenientemente de los bienes exteriores, moderando u ordenando su gusto, su deseo y su amor, de modo tal que se encuentren siempre al servicio de la dignidad personal y de los demás. Esta virtud considera más el afecto del donante que la cantidad dada. Aparece más importante la interioridad del donante que aquello que se entrega. A este acto de dar rectamente se oponen dos vicios: uno por el cual no se da cuando se debe (avaricia) y otro por el que se da lo que no se debe (prodigalidad). 
La liberalidad, como se comprende, rectifica el afecto con relación a la posesión y uso del dinero y aparece como urgente en una época como la nuestra, en la que más bien se enseña y practica lo contrario. En estos tiempos, en razón del predominio que se concede al tener sobre el ser, se cultiva el amor desordenado del dinero (avaricia) a la par que se excita fuertemente al consumidor a gastar lo que no debe (prodigalidad). Defectos opuestos pero que son igualmente cultivados.

Se debe recordar también que tanto la avaricia como la prodigalidad olvidan esa doctrina fundamental de Santo Tomás y de la enseñanza de la doctrina social de la Iglesia relativa al destino universal de los bienes. ${ }^{17}$

En el a. 6 de la cuestión 117 se hace una penetrante observación al señalar que sobre la liberalidad (que regula el uso de las cosas exteriores) se encuentra la templanza (que busca el bien del cuerpo); que la fortaleza y la justicia le son superiores por buscar el bien común, en tanto que ella se ordena al bien privado y que, finalmente la liberalidad, por buscar el bien humano, es inferior a todas aquellas virtudes que tienen por objeto al bien divino. Esto es de interés, porque permite pensar que es imposible pretender los bienes superiores si no se es capaz de lograr los inferiores y que, en consecuencia, la imposibilidad para lograr esta virtud - la liberalidad - que permite el uso ordenado de los bienes exteriores, hará evidente la mayor imposibilidad con respecto a virtudes más excelentes.

De los vicios opuestos a la liberalidad posee especial gravedad la avaricia, que consiste en el deseo inmoderado de poseer y revela un doble desorden:

Uno e inmediato, en cuanto a adquirir y retener los bienes exteriores más de lo debido. En este sentido la avaricia es pecado directamente contra

${ }^{17}$ Esta importante doctrina es expuesta con gran claridad en el Compendio de la Doctrina Social de la Iglesia, 1992, Madrid, Asociación de Editores del Catecismo, 2a. ed., nn. 171-184. Ahí se exponen, en el capítulo IV, los principios de la Doctrina Social de la Iglesia, entre los cuales, además de aquel del Destino Universal de los Bienes, el Principio del Bien Común, el Principio de Solidaridad y el Principio de Subsidiaridad. También se puede ver el suplemento de la revista Signo de los Tiempos intitulado El destino universal de los bienes y el derecho a la propiedad privada. 
el prójimo. Porque, si uno goza de abundancia de bienes, es con la consiguiente penuria de otros, pues los mismos bienes exteriores no pueden ser poseídos a la vez por muchos. Por un segundo aspecto la avaricia supone inmoderación en el apetito inferior de las riquezas, cuando se las ama, desea o goza en ellas inmoderadamente. Entonces el avaro peca contra sí mismo, por lo que implica el desorden, no del cuerpo, como los pecados carnales, sino de los afectos. [q. 118, a. 1, ad 2]

A causa de lo anterior se afirma que la avaricia se opone siempre a la liberalidad y con frecuencia a la justicia. Atenta contra la justicia si se afecta a un derecho ajeno - sobre todo en situaciones sociales de hambre y miseria generalizadas - Y Ya sea en su adquisición o en su conservación. Se dirige contra la liberalidad por implicar el exceso en su deseo, amor o posesión, "aun sin intención de dañar al bien ajeno" (q. 118, a. 3). Estos principios valen para la persona individual al igual que para las sociedades intermedias y los mismos Estados.

Todo esto merece ser recordado y manifiesta la importancia de colocar a la liberalidad y a la avaricia en la perspectiva general de la justicia. Los defectos que representa El avaro de Molière son, en este sentido, más deudores de una mentalidad aristotélica que de una tomista. Y es que la avaricia suele importar el atentado contra la justicia.

Es igualmente interesante recordar que, si bien puede no afectarse a la justicia en la adquisición de los bienes, sí se le puede violar en el amor y uso de los mismos. ¡No basta ganar "honestamente" el dinero para que la justicia quede salvada! Todavía es necesario poseerlo y administrarlo de manera ordenada y racional.

La avaricia, con incidencias profundas en la vida social, supone un apego excesivo a los bienes exteriores, en lo que claramente se opone a la prodigalidad, y es un vicio que consiste en las pasiones desordenadas respecto de tales bienes, ya no por exceso sino por defecto.

La prodigalidad supone siempre la ausencia de armonía en el uso del dinero. Esto, menos frecuente que la avaricia, no deja de manifestar una ausencia de razón en la conducta del hombre.

La prodigalidad no solo es menos frecuente sino que además, añade Santo Tomás, se cura más fácil que la avaricia, ya que suele 
disminuir con la vejez o con la pobreza, situación que pronto se realiza como consecuencia de una prodigalidad inútil.

Termina de este modo el tratamiento de estas virtudes que dependen de la justicia y que son de gran importancia en la vida social. La enumeración de semejantes perfecciones no pretende de ninguna manera ser exhaustiva, con lo que se abre la posibilidad de encontrar nuevas virtudes aplicables y necesarias en una comunidad verdaderamente humana.

Lo que suele suceder, sin embargo, es lo contrario: no solo no se tratan las posibles nuevas virtudes sino que con excesiva frecuencia se olvida la importancia de aquellas que han sido presentadas en este estudio. Es por ello que es siempre saludable y gratificante volver a las enseñanzas auténticas del Doctor Angélico. 
CITAM Derechos Reservados.

La reproducción total o parcial de este artículo se podrá hacer si el ITAM otorga la autorización previamente por escrito. 